\title{
American Society of Anesthesiologists
}

National Cancer Institute

\section{Source}

National Cancer Institute. American Society of Anesthesiologists. NCI Thesaurus. Code C70825.

An educational, research and scientific association of physicians organized to raise and maintain the standards of the medical practice of anesthesiology and improve the care of the patient. 